\title{
Does going abroad benefit my country? Views of highly skilled personnel from Sub-Saharan Africa on brain drain-brain circulation
}

\author{
Patrick Severine Kavenuke and Mjege Kinyota
}

Faculty of Education, Dar es Salaam University College of Education, University of Dar es Salaam

\begin{abstract}
The debate on brain drain-brain circulation has been a longlasting phenomenon of interest among educators in the field of education, in particular, international and comparative education. This long-lasting debate triggered us to rethink about the effects which the concept has on the source country as well as the destination country. The study explored the perceptions of Highly Skilled Personnel (HSPs) residing in Sub-Saharan Africa on HSPs mobility. Respondents for this study comprised of 43 Sub-Saharan African scholars. Data were collected into two phases. First, all the 43 respondents actively participated in a four-day Online Focused Group Discussion (OFGD) moderated by the researchers. The second phase involved online interviews with 12 members who also participated in the first phase. Findings indicated that the majority of respondents favoured brain circulation. This implies a significant shift from brain drain to brain circulation. The socio-economic and political contexts of countries where respondents came from influenced their responses. We suggest that in the current globalized world, instead of restricting HSPs mobility, Sub-Saharan African countries need to create attractive working environment as a means to retain the best talents and motivate those who left to come back. Furthermore, Sub-Saharan African countries must work with diaspora to improve knowledge and business networks that will enable these countries to improve their economies thereby compensating the cost incurred in educating mobile talents. Finally, brain drain-brain circulation agenda should not be viewed in isolation rather as multidimensional in nature due to its overarching countless influencing factors.
\end{abstract}

\author{
Article History \\ Received 13 March 2018 \\ Accepted 10 December \\ 2018
}

Keywords:

Highly Skilled

Personnel (HSPs);

HSPs mobility;

Brain drain;

Brain circulation;

Sub-Saharan

African countries

\section{To cite this paper:}

Kavenuke, P. S. and Kinyota, M. 2018. Does going abroad benefit my country? Views of highly skilled personnel from Sub-Saharan Africa on brain drain-brain circulation. Mkwawa Journal of Education and Development, 2, 1-19. DOI: https://doi.org/10.37759/mjed.2018.2.1.1

Contact: Patrick Severine Kavenuke, patrickkavenuke@yahoo.com. Faculty of Education, Dar es Salaam University College of Education, University of Dar es Salaam 


\section{1.o Introduction}

It is human nature for individuals to seek the place of opportunities where they can easily make a better living. Such experience has led to the theme "brain drain - brain circulation”. Brzozowski (2008) has argued that brain drain-brain circulation debate and its economic implications between sending and receiving countries has been a long-lasting phenomenon of interest among educators and researchers. Brain drain and brain circulation are influenced by globalisation and its resultant impacts. Different scholars (Forstenlechner, 2010; Kauppinen, 2014; Welch \& Zhen, 2008; Weldon et al., 2011) have pointed out that globalisation of education and the increased emphasis on knowledge economies are shaping current views about academic mobility.

Scholars have argued that academic mobility is related to international migration fuelled by the growing number of international students worldwide (Hoffman, 2009; Saxenian, 2005; Varma \& Kapur, 2013). According to Ryan (2011), 35\% of these international students are in the United Kingdom (UK) and the United States (US) alone. This means that there is a polarization of academic and students mobility which divides English speaking countries such as the UK, US and Australia receiving more students and faculty and the rest, particularly, developing countries sending more students and faculty (Hoffman, 2009; Mehrez \& Hamdy, 2010). Nevertheless, both migration and mobility contribute to what the literature has referred to as brain drain, brain gain and brain circulation.

Although brain drain happens between developed countries as well (Brzozowski, 2008), many scholars (Baldwin \& Winters, 2004; Docquier \& Rapoport, 2011; Mehrez \& Hamdy, 2010; Ngoma \& Ismail, 2013; Singh \& Krishna, 2015; Varma \& Kapur, 2013) have tended to consider brain drain from the perspective of HSPs moving from less income countries to higher income countries. Differences in remunerations, research facilities (Muthanna, 2015; Singh \& Krishna, 2015), conflict, lack of employment opportunities, health risks and political instability (Iravani, 2011), geographical distances, colonial ties and languages between source and destination countries (Ngoma \& Ismail, 2013) have been major factors influencing HSPs mobility.

Different phrases have been used to refer to the term brain drain. Such phrases are 'human capital flight' (Ngoma \& Ismail, 2013; Odhiambo, 2013; Okoro, Omeluzor \& Bamidele, 2014; Iravani, 2011), 'high-skill migration or brain migration' (Docquier \& 

Rapoport, 2011), 'brain overflow' and 'brain transfer' (Varma \& Kapur, 2013). Experiences indicate that many of these brain migrants usually have tertiary educational qualifications or their equivalent. In support of that, Ngoma and Ismail (2013) also argued that brain drain concerns with movement of people "with at least tertiary education acquired in the source countries (p. 212)”. In general, understanding of brain drain by the influence of human capital theory, is seen as a loss of productive man power and the investments that produced it (Kauppinen, 2014).

On the other hand, it is brain circulation that has received much attention in the recent years. The term refers to some skilled migrants returning to their home countries, usually with positive contributions (Varma \& Kapur, 2013). Experiences have indicated that there are instances where brain migrants do not physically return to their home countries, yet they serve as mediators connecting their home countries and the recipient countries (Saxenian, 2005). This is usually done by assisting scientific and technical cooperation between the two countries. Furthermore, just like brain drain concept having many phrases describing it, there are a number of concepts substituting the idea of brain circulation. Varma and Kapur (2013) listed such terms as 'brain exchange', 'brain mobility', 'brain pendulum', 'brain return' and 'reverse brain drain'. Thus, it is important to note that, with brain circulation, currently, there is a reverse flow of knowledge, skills and money which brain migrants are sending to their home countries. In that regard, it is not surprising that, what was once referred to as brain drain is now seen as brain circulation.

As stated earlier, the movement of HSPs begins when they go abroad for studies (Saxenian, 2005; Varma \& Kapur, 2013). Singh and Krishna (2015) argued that, historically, HSPs refer to movement between countries with different degrees. In the context of India, for example, the mobility of HSPs has gone through some phases. Such phases are from brain drain to brain gain in 1960's to 1980's and later brain circulation in the 1990's (Brzozowski, 2008; Singh \& Krishna, 2015). The move to brain circulation was mainly due to a rapid development of information and communication technologies and computer software. Such developments are said to have reversed mobility trends in countries such as India (Singh \& Krishna, 2015). Therefore, the move to brain circulation has made people to start considering brain migrants as blessings to the sending countries. This happens when the sending countries benefit from brain drain as a result of brain circulation. In support of this, 
Brzozowski (2008) added that the potential gains of brain drain and its resultant brain circulation are sometimes higher than the costs.

\subsection{The Present Study}

From 1980's to 1990's many HSPs returned to their home countries (Singh \& Krishna, 2015; Ziguras \& Gribble, 2015) indicating important shifts of HSPs mobility patterns. However, this pattern did not happen in all countries at the same pace. For example, not only sub-Saharan Africa has experienced an outflow of her talents to Europe and America but also there is lack of systematic records about the scope and impacts of brain drain (Odhiambo, 2013). In higher education only, it was estimated in the World Bank report of 2006 that about 23,000 qualified academics left Sub-Saharan Africa every year resulting into serious shortages of academics in higher education institutions (Odhiambo, 2013). Kalipeni, Semu and Mbilizi (2012) identified the health sector as the most affected sector in Sub-Saharan Africa where qualified doctors and nurses migrate to North America and Europe in masses every year. It is also estimated that 16 million Sub-Saharan Africans live abroad and a big chunk of them constitute HSPs (Kaba, 2011). With regard to brain drain, Okoro et al., (2014) note adverse impacts in Nigeria where a total of 315 librarians emigrated to developed countries resulting into serious shortages of librarians in Nigerian universities.

\subsection{Study Purpose and the Research Question}

Given the fact that brain drain - brain circulation is not evenly distributed at global scale, this study intended to find out how HSPs mobility is perceived by HSPs residing in Sub-Saharan Africa. Furthermore, the motivation to conduct this study emerged from the fact that there is no substantial existing data about HSPs mobility and its impacts in sub-Saharan Africa. This study limited itself to HSPs mobility from SubSaharan African countries to developed countries as opposed to within continent mobility. In addition, using a dominant definition of brain drain, the movement of HSPs from less developed to highly developed countries, this study sought to include only brain drain and brain circulation as phenomena that are expected in most SubSaharan African countries. Thus, this study was guided by a general research question "How is HSPs mobility perceived by HSPs residing in Sub-Saharan Africa?". Specifically, the study intended to answer the question "how good or bad is HSPs mobility as perceived by HSPs residing in Africa?”. Also, the study intended to answer 
the question "what do HSPs perceive to be the attributing forces to the phenomenon of brain drain in Africa?”

\subsection{The Brain Drain - Brain Circulation Debate: A Theoretical}

\section{Framework}

As stated earlier, so far the debate on the question of HSPs mobility has been an endless discussion. There have been different views and misperceptions about the impacts of talent mobility. In that regard, the purpose of this study was to bring this debate to life by asking a question 'How is HSPs mobility perceived by HSPs residing in Sub-Saharan Africa?' Changing patterns of HSPs mobility challenge old views of brain drain. For instance, instead of blocking international mobility of HSPs, developing countries are urged to create attractive environment of HSPs at home and abroad. According to Beine, Docquier and Rapoport (2008) the impact of HSPs mobility depend on the balance between beneficial 'brain effects' and detrimental 'drain effects'. Beneficial 'brain effects' means higher expected returns from abroad boost investments in education in source countries whereas detrimental 'drain effects' means movements of HSPs hurt the economies in source countries. In other words, the impact of HSPs mobility depends on which effect dominates in a country.

Different countries have responded differently to the phenomenon of brain drain. While some countries have set specific regulatory mechanisms and beneficial strategies such as diaspora engagement, other countries have not set policies to deal with the phenomenon (Singh \& Krishna, 2015; Teferra, 2005). With rapid development in information and communication technologies as a result of globalisation, Teferra (2005) argued that the impacts of brain drain that were once due to physical distance between migrated HSPs and source countries can be strategically dealt with. This can be in form of researchers and scholars from distant localities easily sharing ideas and experiences (Gaillard, Gaillard \& Krishna, 2015). In the literature, the term 'circulation' at the beginning implied two main trends in the mobility of HSPs between sending and receiving countries as Gaillard et al., (2015) put it:

First, the expected return of expatriated students and professionals with increased knowledge, skills and expertise closely associated with 'return policies'. The Second is the possible reservoir of expertise encompassed by the diasporas abroad that could be of interest for the home countries 
Does going abroad benefit my country? Recently, however, the term circulation has been used to general international mobility of HSPs with the assumptions that, regardless of localities, different countries can benefit from a pool of migrating HSPs somewhere else. To use Gaillard et al., (2015) phrase, HSPs have become 'global citizens' operating in different locations and communicating with others in more than one country. However, these reversing trends are not celebrated everywhere and do not deny the existence of notable brain drain patterns in some countries. For example, Gaillard et al., (2015) noted that HSPs in Morocco do not return back to their country due to poor working conditions at home. Moreover, the country has not been able to effectively tap on the talents from diaspora. Defined as people who live abroad but are physically and/or emotionally attached to their country and who are interested with the development of their home countries (Mehrez \& Hamdy, 2010) diasporas' gained skills and experience can be potential in sending countries. For example, in a study of Egyptians diaspora contributions to their home countries, Mehrez and Hamdy (2010) found that diaspora facilitated technology transfer, business and entrepreneurial links, skill acquisition and remittances.

In that respect, brain circulation is recently gaining attraction than brain drain due to its advantages that outshine the disadvantages of brain drain. Table 1 summarizes the tenets of brain drain-brain circulation debate.

\section{Table 1: Conceptions of Brain Drain and Brain Circulation}

\section{Brain Drain Conceptions}

a) Permanent loss of human capital to sending countries

b) Wealthy countries stealing some of the best talents from developing countries

c) Dividing countries into human resource-rich and human resourcepoor

d) A threat to international integration

e) A threat to economic progress of developing countries

f) The best brains that developing countries have trained should not leave
Brain Circulation Conceptions

a) HSPs gain international experiences and benefits countries of origin

b) Return of HSPs with additional skills and experiences acquired abroad

c) The more the countries and organisation HSPs work with, the more the skills and experience they acquire

d) HSPs mobility should not be blocked. It creates an environment to attract HSPs at home and from abroad

e) Creation of scientific and business networks

f) Remittances sent to dependants in home countries promote human capital investments in source countries 
Does going abroad benefit my country? Given that brain drain was mainly informed by human capital theory, in the 1960 s the dominant perspective was to strongly condemn the movement of HSPs from poor to rich countries (Gaillard et al., 2015). There was no any thorough analysis done in this perspective to find out the advantages of HSPs mobility to individuals as well as to the sending countries. However, from Table 1, we note numerable positive contributions of brain drain that is expressed in form of brain circulation. Nevertheless, to benefit from HSPs mobility, sending countries have to invest in order to attract diasporas to come back home. For instance, Ziguras and Gribble (2015) asserted that since 1990's Singapore has enhanced cooperation with HSPs in the diaspora. Singapore has also created employment opportunities for returnees.

\section{2.o Methodology}

The study employed a qualitative approach to collect data using an online discussion forum named "United States of Africa". This online discussion forum included members from different Sub-Saharan African countries, we, the researchers being included in the forum as discussants. Respondents belonged to different professions and had at least a bachelor's degree making them fit in the definition of HSPs as defined by Ngoma and Ismail (2013). Respondents' age ranged from 27-43 years. Forty-three respondents actively participated in this study. Of all the 43 respondents, only one (1) was a female. For the purpose of anonymity and presenting findings in verbatim quotations from respondents (Hett \& Hett, 2013; Holliday, 2013; Shamim \& Qureshi, 2013), the respondents were given pseudo names such as Sun, Mercury, Mars, Jupiter, Moon and Galaxy, to mention a few. Table 2 presents respondents' information by country.

Table 2: Study Respondents

\begin{tabular}{|c|c|c|c|c|}
\hline Country & $\begin{array}{l}\text { Number of } \\
\text { respondents }\end{array}$ & $\begin{array}{c}\text { Respondents with } \\
\text { Post-graduate } \\
\text { degree acquired at } \\
\text { home }\end{array}$ & $\begin{array}{c}\text { Respondents with } \\
\text { Post-graduate } \\
\text { degree acquired } \\
\text { abroad } \\
\end{array}$ & Interviewed \\
\hline Tanzania & 7 & $3\left(1^{*}\right)$ & $1^{*}$ & 2 \\
\hline Namibia & 4 & $2\left(1^{*}\right)$ & $1^{*}$ & 2 \\
\hline Kenya & 3 & $1^{*}$ & o & 1 \\
\hline Zambia & 6 & 2 & $3\left(1^{*}\right)$ & 1 \\
\hline South Africa & 9 & $5\left(1^{*}\right)$ & $2\left(1^{*}\right)$ & 2 \\
\hline Uganda & 2 & None & 1 & None \\
\hline Rwanda & 3 & 1 & $1^{*}$ & 1 \\
\hline Zimbabwe & 4 & $2\left(1^{*}\right)$ & 1 & 1 \\
\hline Nigeria & 2 & 1 & None & None \\
\hline Ghana & 3 & $1^{*}$ & $1^{*}$ & 2 \\
\hline
\end{tabular}


*Indicates those who were interviewed

We employed two research methods where all the 43 respondents participated in an Online Focus Group Discussion (OFGD) and 12 of them were selected to partake in an online semi-structured interview. The OFGD ranged from 35 to 40 minutes, whereas online semi-structured interviews ranged from 20 to 25 minutes. We joined this online discussion forum two years ago and have been active members of this online discussion forum that discusses matters related to Africa's socio-economic and political development. In the interview and OFGD, English language was preferred because it is the language that many respondents understood. We introduced the topic by asking respondents' willingness to participate and explained the purpose of our discussion. To guide the discussion, we asked respondents to focus on the topic and defined some of concepts such as HSPs. Following Holliday (2013) suggestions, respondents were told that the discussion was for the purpose of this research only and that they will be protected by keeping their identities anonymous throughout this research. The discussion was open for four days (from $5^{\text {th }}-8$ th January 2018) with us, the researchers guiding it with follow up questions and reminders about the focus of the discussion.

This study used quota sampling which involves dividing a population into strata based on the characteristics of interest (Ary, Jacobs, Sorensen \& Walker, 2010). This enabled researchers to divide HSPs with international experience gained because of studying or working abroad and those without experience. It was the researchers' assumption that international experience may have influence on the views that HSPs residing in Sub-Saharan Africa hold about HSPs mobility. Thus, we selected a sample of twelve respondents to participate in online interviews. Of all the twelve respondents involved in the interview, we selected six (6) who had no international experience and six (6) who had international experiences gained by studying abroad in their post-graduate studies. Both OFGD and online interviews were transcribed, coded, sorted and categorised using 'constant comparison method'. According to Charmaz (2010), this method enables researchers to compare data from different sources of data and units of analysis. The purpose of using this method was to generate themes related to the research questions and a theoretical framework. 


\section{3.o Findings}

Does going abroad benefit my country?

As stated earlier, the purpose of this study was to answer the main research question 'How is HSPs mobility perceived by HSPs residing in Sub-Saharan Africa? Specifically, the study intended to answer the question "how good or bad is HSPs mobility as perceived by HSPs residing in Africa?” Also, the study intended to answer the question "what do HSPs perceive to be the attributing forces to the phenomenon of brain drain in Africa?" There were varied opinions about HSPs mobility which all 43 respondents expressed during OFGD and later with twelve (12) respondents who participated in online interviews. Majority of respondents preferred to use the phrase 'brain drain' than HSPs mobility. Our interpretation was that brain drain is a term familiar to many HSPs even those without international experience and/or have taken any course in higher education.

\subsection{Brain drain: Good or bad?}

One of the research questions that this paper intended to answer was "how good or bad is HSPs mobility as perceived by HSPs residing in Africa?" During OFGD, respondents were divided by whether brain drain is bad or good for Sub-Saharan Africa as part of the continent. From the analysis of transcripts of the OFGD, 19 (44.2\%) respondents were in favour of brain drain, seven (7) (16.3\%) were against brain drain while 17 (39.5\%) took a neutral stance by looking at both challenges and opportunities of brain drain.

Those who supported brain drain had several arguments. One among them was that brain drain has advantages in terms of diaspora who send money to their home countries. While none of the respondents related money to investments in education, there was a general agreement that money could be used to boost the economy (which one respondent expressed as 'crumbling economy') of some Sub-Saharan African countries. During OFGD, one respondent from Zimbabwe expressed that:

...you cannot survive without dollars [US Dollars] in Zimbabwe. Where do the dollars come from? They come from people living abroad. Give me a break! In fact, parents encourage their sons and daughters to go abroad. This is the very reason I am a Zimbabwean but I leave in the Republic of South Africa (Sun, OFGD, $6^{\text {th }}$ January 2018).

With regard to the question of remittances, there was no difference between countries among those who were in favour of brain drain but there were differences between those who had and those who lacked international experiences. While those who had 
international experiences were very articulate on the subject by drawing examples from different countries and even mentioning related terminologies such as remittances, those without international experience expressed their ideas using simple and plain language. To highlight on this, one respondent from Zambia with two years of international experiences studying in the United Kingdom had this to say during OFGD:

I think brain drain is a phenomenon that we cannot do away with it. It comes with positive repercussions to us in different forms such as remittances. It is through remittances where many of our relatives are saved from the economic shock persisting in our countries... Consider countries such as Somalia and Eritrea... (Mars, OFGD, $6^{\text {th }}$ January 2018).

On the other hand, those without international experiences were represented by a respondent from Tanzania. In an interview, the respondent underscored that:

I have heard people who study abroad send money to the countries they come from. If they really do that, I think brain drain is of paramount. To me, this experience is just like us who leave in urban areas sending money to our parents in the rural areas (Jupiter, Interview, $8^{\text {th }}$ January 2018).

Findings from OFGD were supported by those from interviews. Although the term remittance was not mentioned, twelve interviewed respondents were in the opinion that remittances could be a source of income for sending countries. However, four (4) (33.3\%) of the 12 respondents were not convinced that remittances could fill that gap of the loss that many Sub-Saharan African countries encounter as a result of brain drain. To support this idea, a respondent from Ghana with three years of experience in the United States of America highlighted that:

... it happens that sometimes life abroad is hard. There are days we do not get enough money for ourselves not even to think of talking of sending money back home. So, to me, it is more of the individual matter as I find the disadvantages of brain drain surpassing the advantages of remittances (Galaxy, interview, $7^{\text {th }}$ January 2018).

Another argument reflected the individual benefits of education. Those who support brain drain had a concern that education must benefit those who have it and that individuals should be free to find jobs anywhere where their education is valued. They argued that many people leave because their countries do not provide the best for them and that is their country's fault. Other respondents - nine (9) respondents in an OFGD and two (2) interviewees - asserted that unemployment problem in several SubSaharan African countries is the reason that make people leave their countries to 
abroad for better job deals. While shouting, one respondent from Kenya had this to say during an interview:

Stop kidding me! Should I stay home because I have to be patriotic? If the government can't give me a job, I have to find it elsewhere. By the way, by leaving the country, I reduce the number of unemployed people in my country (Moon, Interview, $8^{\text {th }}$ January 2018).

Only four (4) respondents in an OFGD and one (1) in an interview saw brain drain as a tool through which valuable knowledge from developed countries can penetrate into the developing countries. They expressed their opinions that those who leave their countries can, in the future, decide to come back and share knowledge acquired abroad. One respondent during interview thought that brain drain can connect SubSaharan African countries with developed countries by the transfer of valuable knowledge facilitated by those who move to other countries. The respondent related brain drain to globalisation which according to him, it is a driving force of HSPs mobility and that even if countries wish to block talent mobility, globalisation will prevent them from doing that.

Most of those who opposed it, both from online interviews and OFGD were driven by patriotic sentiments. They also had several arguments one being the fact that, those who go abroad represent the best talents that could benefit their home countries. They even attacked those who saw anything good in brain drain as lacking patriotism. This transcript from OFGD could express the anger coming from this respondent from Namibia:

Africa's development will be possible if and only if we, the educated are patriotic. How can we support non-patriotic behaviours [brain drain] and expect development? [Mentioned the name of another respondent], there is no reason so ever for one to leave his/her country and go to find a job in Europe and North America some of which [jobs] are humiliating. Let us be patriotic... (Star, OFGD, $7^{\text {th }}$ January 2018).

This view was supported by other respondents who opposed brain drain. While others condemned lack of patriotism by giving other arguments, others just perceived people leaving their countries as lacking patriotism. This was reflected by a failure to respond back using precise explanation to another respondents who reacted by asking them about what people should do if they are highly educated and their countries are not in a position to offer them better jobs.

Moreover, majority of respondents pointed out the cost that Sub-Saharan African countries incur as a result of loss of their talents. This was expressed by both during 
interviews and OFGD where, for example, 23 respondents (16 OFGD and seven (7) interviewees) agreed that the cost of training an individual is high. Although none of the respondents provided an exact figure of such training costs, they were concerned with the fact that sub-Saharan African countries spend a lot of money in educating their citizens, sometimes using loans from developed countries. As such, brain drain is seen as the loss of money that could be used in other sectors instead of training people who end up benefiting other countries.

Two respondents during an OFGD went further suggesting that developed countries should be asked to pay the cost for brain drain. Thirteen respondents - nine (9) respondents from OFGD and four (4) interviewees - saw the impacts of brain drain beyond training costs. They perceived the 'evil brain drain' [interview transcript] as a result of the talents being taken by developed countries leaving untalented people in developing countries. They believed those who are most talented and from important economic sectors are more likely to attract job markets in developed countries. Given the fact that Sub-Saharan Africa needs talents in important sectors such as medicine and technology, they found brain drain as an extreme path that has to be reversed.

The last argument which was reflected from OFGD and online interviews was the idea of neo-colonialism that a few respondents - four (4) in OFGD - raised. They argued that brain drain is a continuation of history by developed countries snatching the best resources from poor countries. They considered it as a deliberate act by developed countries to create policies that attract the best talents from Sub-Saharan Africa and other developing countries. Reflected in this argument, was the idea that sometimes it is not those with talents who are willing to leave their countries to search for better jobs in developed countries rather it is developed countries that create mechanisms for persuading talented people from Sub-Saharan Africa.

\subsection{Who to blame and what to be done?}

The second research question attempted to answer the question "what do HSPs perceive to be the attributing forces to the phenomenon of brain drain in Africa?" In other words, the research question focused on exploring the forces that influence the movement of talents from sub-Saharan Africa to developed countries. Majority of respondents - 29 respondents from OFGD and seven (7) interviewees - regardless of their international experiences blamed the sending countries' economic conditions. Also, they blamed the policies operating in their home countries for not addressing the 

socio-economic and political matters of the countries seriously as major reasons for brain drain. Thus, they cited examples such as higher unemployment rates, low salaries, payment delays, poor working conditions and lack of good policies for attracting those who left as driving forces for the mobility of HSPs from Sub-Saharan Africa to developed countries.

In addition, the respondents went extra length by offering some suggestions for improvement in to retain the talents in home countries. The suggestions mainly emanated from the forces that were considered as influencing HSPs' mobility. For instance, during interviews three (3) respondents suggested that Sub-Saharan African countries should set good policies for attracting those who left to come back and contribute to their countries' economies. Nevertheless, there were variations between countries regarding this matter that was reflected during OFGD and online interviews.

With regard to this, respondents coming from countries with high unemployment rates such as Nigeria and those from countries whose economy is close to collapse such as Zimbabwe tended to defend brain drain and blamed their governments than lacking patriotism among those who migrate. To highlight on this, a respondent from Zimbabwe succinctly underscored that:

... Mmmh! guys stop being too judgmental. There is no patriotism in hunger ... how can I stay in Zim [Zimbabwe], a country in such economic recession? I know you are saying this because you are coming from countries with stable economies. I think you do not know the situation in Zim (Mercury, OFGD, $5^{\text {th }}$ January 2018).

The quotation above represents the feelings that the respondent had with regard to the connection between brain drain and its positive contribution to individuals and families in the home countries.

\section{0 Discussion}

From the findings presented above several points are worthwhile discussing. First, the fact that the majority of respondents (34 out of 43) expressed positive views about brain drain is surprising, given the nature and aims of the forum from which all respondents are part of it. The forum used in this study was formed for discussing matters related to Pan-Africanism. Thus, respondents who were by virtue of being in the forum regarded as patriotic, they were also expected to present themselves as patriotic during discussion. Given the purpose of the forum, findings unveiled that some respondents who were not in favour of brain drain condemned those who 

supported it for lacking patriotism. Surprisingly, these respondents blamed those in favour of brain drain even when they could not support well their claims as to why they see brain drain as a bad phenomenon.

Moreover, for respondents with an inclination toward brain circulation, their preference could not be confirmed because majority of them did not have a good command of what entails HSPs mobility. For example, while research has shown some advantages of brain drain to sending countries such as knowledge contribution from diaspora (Ortiga, Chou, Sondhi \& Wang, 2018; Wiesel, 2014; Zweig et al., 2008), return of HSPs with valuable and new skills and experiences (Chand, 2018; Yoon, Rha, Kim \& Hwang, 2013) and benefiting from the general pool of HSPs in an information age (Teferra, 2005), the majority of respondents discussed positive impacts of brain drain mainly in terms of remittances. Furthermore, none of the respondents could make a connection between remittances and investment in education. Beine, Docquier and Rapoport (2008) asserted that to be able to understand the resultant effects of brain drain, one must be conversant with the formal statistics of whether HSPs mobility hurts or boosts economies in source countries. With regard to this, we assume that respondents' insufficient knowledge about issues and available statistics on HSPs mobility in Sub-Saharan Africa might have influenced their position regarding the matter.

Although the number of respondents is not substantial to make certain conclusions, it was noted from respondents' reactions that countries' socio-economic and political contexts seemed to divide respondents in the debate. The favour of brain drain combined with anger expressed by respondents from Nigeria and Zimbabwe may indicate the frustrations that socio-economic and political contexts poses. Their expressions appeared to support previous studies (Chand, 2018; Fioratta, 2015; Ortiga et al., 2018; Tahir, Khan \& Shah, 2015). These studies found that unfavourable socioeconomic and political conditions such as unemployment, unlimited career opportunities and political instability in source countries are among the factors reinforcing brain drain.

Therefore, it is not surprising for these respondents to favour brain circulation debate claiming that they did not see any point for talented individuals to remain in a country where employment and remuneration is a problem. Again, this appears to support 

Ngoma and Ismail (2013) assertion that lack of policies to attract HSPs at home in most sub-Saharan African countries is the driving force for brain drain. In line with this assertion, during interviews and OFGD, the majority of respondents suggested that low salaries and poor working conditions were behind the reasons many talented individuals leave their countries. However, the fact is that although governments have limited influence on individuals' decisions to leave their countries (Forstenlechner, 2010), they can set policies for attracting expatriates.

In addition to that, a tendency to consider brain drain as a systemic as opposed to individual problem was noticed. Majority of respondents blamed government policies, either at home or destination countries, for fuelling HSPs mobility. In other words, the act of leaving a developing country to search for better jobs in developed countries is not seen as part of individuals' formation rather as combination of external factors such as lack and presence of attractive working environment at home and destination countries respectively. For example, the majority of respondents thought the best talents would not find a reason to leave their countries if economies in their home countries were stable enough to accommodate their demands. If these claims are to be certain, they have innumerable implications for policy making in Sub-Saharan African countries.

This implies that Sub-Saharan African countries can reverse brain drain by creating attractive environment for their talents to remain and those who left to come back. As Singh and Krishna (2015) have pointed out that, Sub-Saharan African countries can follow the Indian path where the development of Information and Communication Technologies (ICT) and software technologies is reversing brain drain to substantial conditions. Considering other options during policy development can also offer possibilities and hopes for Sub-Saharan Africa's development. For example, while embarking in a long process of creating attractive working and study environment, Sub-Saharan African countries can create mechanisms for dealing with 'diasporic knowledge networks' which according to Welch and Zhen (2008, p. 519), have been pivotal in promoting socio-economic and political developments in source countries.

\section{5.o Conclusions}

This study explored the views of HSPs residing in Sub-Saharan Africa about brain drain-brain circulation in Africa. Findings showed that the majority of respondents do not see brain drain as a bad phenomenon for Sub-Saharan Africa. Given the fact that 

an OFGD forum used in this study was composed of respondents with Pan-African orientation, their views, especially their favour for brain drain, may indicate a shift from brain drain to brain circulation. This claim can be strengthened by the fact that these respondents had little or no knowledge about higher education as a field of study, belonged to different professions and had varied international experiences.

This study offers several policy related suggestions relevant to Sub-Saharan Africa's development context. First, in the current globalised world, HSPs mobility is inevitable and the best way to do is to create attractive working and investment environment as a means to retain the best talents and motivate those in diaspora to come back. This will be possible by putting in place policies for addressing the issue of brain drain. Second, Sub-Saharan African countries must work with diaspora, as Mehrez and Hamdy (2010) have suggested, to improve knowledge and business networks that will enable these countries to improve their economies thereby compensating the cost incurred in training those who left the source countries. Furthermore, we conclude that the issue of brain drain should not be viewed in isolation rather as a challenge that is multidimensional in nature and influenced by many factors. The socio-economic and political factors in a given country produce a combination of factors that influence HSPs mobility. For that matter, to address the problem of brain drain we recommend the policies to reconsider both internal and external factors contributing to brain drain phenomenon.

Finally, for future research purpose, we recommend almost similar studies to be conducted especially in countries such as Tanzania, where we were not able to locate literature regarding the topic. This will add value to the little existing body of knowledge. Moreover, since this study focused on respondents' views, future studies may focus on examining how the perceived views influence respondents' behaviour. Such influences may be recommending others to go abroad than remaining in the home country or the vice versa.

\subsection{Benefits and limitations of the study}

Although the study is with benefits that override the limitations, this study is also without limitations and it is worth listing them. First, although this study involved an insufficient number of respondents from a few sub-Saharan African countries, it highlights the views of HSPs residing in Sub-Saharan Africa about brain drain. Second, while the study cannot be used to generalise the views of many Sub-Saharan Africans 

nor does it provide statistical data about brain drain in Sub-Saharan Africa, it offers some tips for policy improvement for Sub-Saharan African countries to retain their best talents. Third, to keep all respondents in focus, the researchers defined some of the terms. In one way or another, this might have influenced some of the expression of some views from the respondents.

\section{Acknowledgements}

Special thanks should go to the respondents who willingly agreed to participate in this study. We also acknowledge the support provided by Professor David Turner (PhD.) and Dr. Lorin Yochim (PhD.) for proofreading this work.

\section{References}

Ary, D., Jacobs, L. C., Sorensen, C. K., \& Walker, D. A. (2010). Introduction to research in education (8th ed.). Betmont, Carfornia: Wadsworth Cengage Learning.

Baldwin, R. E., \& Winters, L. A. (2004). Challenges to globalization: An overview. National Bureau of Economic Research, 1-14. Retrieved from http://sro.sussex.ac.uk/26407/

Beine, M., Docquier, F., \& Rapoport, H. (2008). Brain drain and human capital formation in developing countries: Winners and losers. The Economic Journal, $118,631-652$.

Brzozowski, J. (2008). Brain drain or brain gain? The new economics of brain drain reconsidered. https://doi.org/http://ssrn.com/abstract $=1288043$

Chand, M. (2018). Brain drain, brain circulation, and the African diaspora in the United States. Journal of African Business, 1-15. https://doi.org/10.1080/15228916.2018.1440461

Charmaz, K. (2010). Grounded theory: Objectivist and constructivist methods. In W. Luttrell (Ed.), Qualitative educational research: Readings in reflexive methodology and transformative practice (pp. 183-207). New York: Routledge.

Docquier, F., \& Rapoport, H. (2011). Globalization, brain drain and development. Journal of Economic Literature, 1-60. https://doi.org/10.1257/jel.50.3.681

Fioratta, S. (2015). Beyond remittance: Evading uselessness and seeking personhood in Fouta Djallon, Guinea. American Ethnologist, 42(2), 295-308. https://doi.org/10.1111/amet.12131

Forstenlechner, I. (2010). Brain drain in developed countries: Can governments do anything to bring expatriates back? Public Policy and Administration, 25(2), 156-174. https://doi.org/10.1177/0952076709356853

Gaillard, J., Gaillard, A.-M., \& Krishna, V. V. (2015). Return from migration and circulation of highly educated people: The never-ending brain drain. Science, Technology and Society, 20(3), 269-278. https://doi.org/10.1177/0971721815597168

Hett, G., \& Hett, J. (2013). Ethics in intercultural research: Reflections on the 

challenges of conducting field research in a Syrian context. Compare, 43(4), 496515. https://doi.org/10.1080/03057925.2013.797753

Hoffman, D. M. (2009). Changing academic mobility patterns and international migration: What will academic mobility mean in the 21st century? Journal of Studies in International Education, 13(3), 347-364.

Holliday, A. (2013). The politics of ethics in diverse cultural settings: Colonising the centre stage. Compare, 43(4), 537-554. https://doi.org/10.1080/03057925.2013.797775

Iravani, M. R. (2011). Brain drain problem: A review. International Journal of Business and Social Science, 2(15), 284-289. Retrieved from http://ijbssnet.com/journals/Vol_2_No_15_August_2011/32.pdf

Kaba, A. J. (2011). The status of Africa's emigration brain drain in the 21st century. Western Journal of Black Studies, 35(3), 187-195.

Kalipeni, E., Semu, L. L., \& Mbilizi, M. A. (2012). The brain drain of health care professionals from sub-Saharan Africa: A geographic perspective. Progress in Development Studies, 12(2-3), 153-171. https://doi.org/10.1177/146499341101200305

Kauppinen, I. (2014). Different meanings of "knowledge as commodity" in the context of higher education. Critical Sociology, 4O(3), 393-409. https://doi.org/10.1177/0896920512471218

Mehrez, D., \& Hamdy, H. (2010). Skilled Egyptian diaspora contributions to Egypt. Education, Business and Society: Contemporary Middle Eastern Issues, 3(4), 250-261. https://doi.org/10.1108/17537981011089550

Muthanna, A. (2015). Quality education improvement: Yemen and the problem of the "brain drain." Policy Futures in Education, 13(1), 141-148. https://doi.org/10.1177/1478210314566734

Ngoma, A. ., \& Ismail, N. . (2013). The impact of brain drain on human capital in developing countries. South Africa Journal of Economics, 81(2), 211-225.

Odhiambo, G. O. (2013). Academic brain drain: Impact and implications for public higher education quality in Kenya. Research in Comparative and International Education, 8(4), 510-523. https://doi.org/10.2304/rcie.2013.8.4.510

Okoro, C. C., Omeluzor, S. U., \& Bamidele, I. A. (2014). Effect of brain drain (human capital flight) of Librarians on service delivery in some selected Nigerian universities. SAGE Open, 4(3), 1-11. https://doi.org/10.1177/2158244014541131

Ortiga, Y. Y., Chou, M., Sondhi, G., \& Wang, J. (2018). Academic “centres ,” epistemic differences and brain circulation. International Migration, 56(5), 90-105. https://doi.org/10.1111/imig.12354

Ryan, J. (2011). Teaching and learning for international students: Towards a transcultural approach. Teachers and Teaching, 7(6), 631-648.

Saxenian, A. L. (2005). From brain drain to brain circulation: Transnational communities and regional upgrading in India and China. Studies in Comparative International Development, $40(2)$, $35-61$. 
https://doi.org/10.1007/BFo2686293

Shamim, F., \& Qureshi, R. (2013). Informed consent in educational research in the South: Tensions and accommodations. Compare, 43(4), 464-482. https://doi.org/10.1080/03057925.2013.797729

Singh, J., \& Krishna, V. V. (2015). Trends in brain drain, gain and circulation: Indian experience of knowledge workers. Science, Technology and Society, 20(3), 300321. https://doi.org/10.1177/0971721815597132

Tahir, M., Khan, I., \& Shah, A. M. (2015). Foreign remittances, foreign direct investment, foreign imports and economic growth in Pakistan: A time series analysis. Arab Economic and Business Journal, 1O(2), 82-89. https://doi.org/10.1016/j.aebj.2015.06.001

Teferra, D. (2005). Brain circulation: Unparalleled opportunities, underlying challenges, and outmoded presumptions. Journal of Studies in International Education, 9(3), 229-250. https://doi.org/10.1177/1028315305277619

Varma, R., \& Kapur, D. (2013). Comparative analysis of brain drain, brain circulation and brain retain: A case study of Indian Institutes of Technology. Journal of Comparative Policy Analysis: Research and Practice, 15(4), 315-330. https://doi.org/10.1080/13876988.2013.810376

Welch, A. R., \& Zhen, Z. (2008). Higher education and global talent flows: Brain drain, overseas Chinese intellectuals, and diasporic knowledge networks. Higher Education Policy, 21, 519-537. https://doi.org/10.1057/hep.2008.20

Weldon, P. A., Rexhepi, J., Chang, C., Jones, L., Layton, A., Liu, A., ... Torres, C. A. (2011). Globalization and higher education in Southern California : views from the professoriate. Compare: A Journal of Comparative and International Education, 41(1), 5-24. https://doi.org/10.1080/03057925.2010.532360

Wiesel, T. (2014). Fellowships: Turning brain drain into brain circulation. Nature, 510(7504), 213-4. from http://scholar.google.com/scholar?hl=en\&btnG=Search\&q=intitle:Turning+bra in+drain+into+brain+circulation\#3\%5Cnhttp://www.ncbi.nlm.nih.gov/pubme $\mathrm{d} / 24926501$

Yoon, I., Rha, K., Kim, J., \& Hwang, J. (2013). Brain circulation of South Korean students in Japan and China. Asian and Pacific Migration Journal, 22(4), 501525 .

Ziguras, C., \& Gribble, C. (2015). Policy responses to address student "brain drain": An assessment of measures intended to reduce the emigration of Singaporean international students. Journal of Studies in International Education, 19(3), 246-264. https://doi.org/10.1177/1028315314561121

Zweig, D., Fung, C. S., \& Han, D. (2008). Redefining the brain drain: China's “Diaspora option." Science Technology \& Society, 13(1), 1-33. https://doi.org/10.1177/097172180701300101 